\section{A Modified Inverted Omega Incision for Surgical Treatment of Gynecomastia}

\section{To the Editor:}

Gynecomastia is a benign enlargement of male breast. According to tissue composition, it is usually classified into 3 types: true gynecomastia (glandular), pseudogynecomastia (fatty-glandular), and false gynecomastia (fatty). According to the size of the breast and to the amount of redundancy skin, we use $\mathrm{Si}$ mon's classification. ${ }^{1}$

Many incisions and surgical technique have been described and applied by different authors according to the type and severity of gynecomastia: from suction-assisted lipectomy for fatty forms ${ }^{2}$ together with the eventual surgical excision of glandular tissue ${ }^{3}$ for true gynecomastia to skin resection and eventually free nipple graft for highgrade gynecomastia. ${ }^{4,5}$

For Simon's grade 1 and 2A, we use subcutaneous mastectomy and a modification of omega incision described by Simon et $\mathrm{al}^{1}$ in 1973 . The classic inferior semicircular intra-areolar incision described by Webster ${ }^{6}$ and Dufourmentel $^{7}$ is enlarged by lateral and medial extensions.

We modified this approach by adding the removal of a crescent of skin under the $\omega$ incision (Fig. 1) to improve surgical exposure and hemostasis (advantages of omega incision) and to improve the final aspect of the areola, avoiding the tendency to oval scarring due to the excess of skin after mastectomy at the inferior pole of the nippleareolar complex.

In our experience, we think this simple technique modification could improve esthetic outcomes without lengthening surgical risks and time.

Alessandro Thione, MD Luigi Valdatta, MD, FACS Alessandra Gottardi, MD

Plastic Surgery Unit Ospedale di Circolo University of Insubria Varese, Italy althione@libero.it

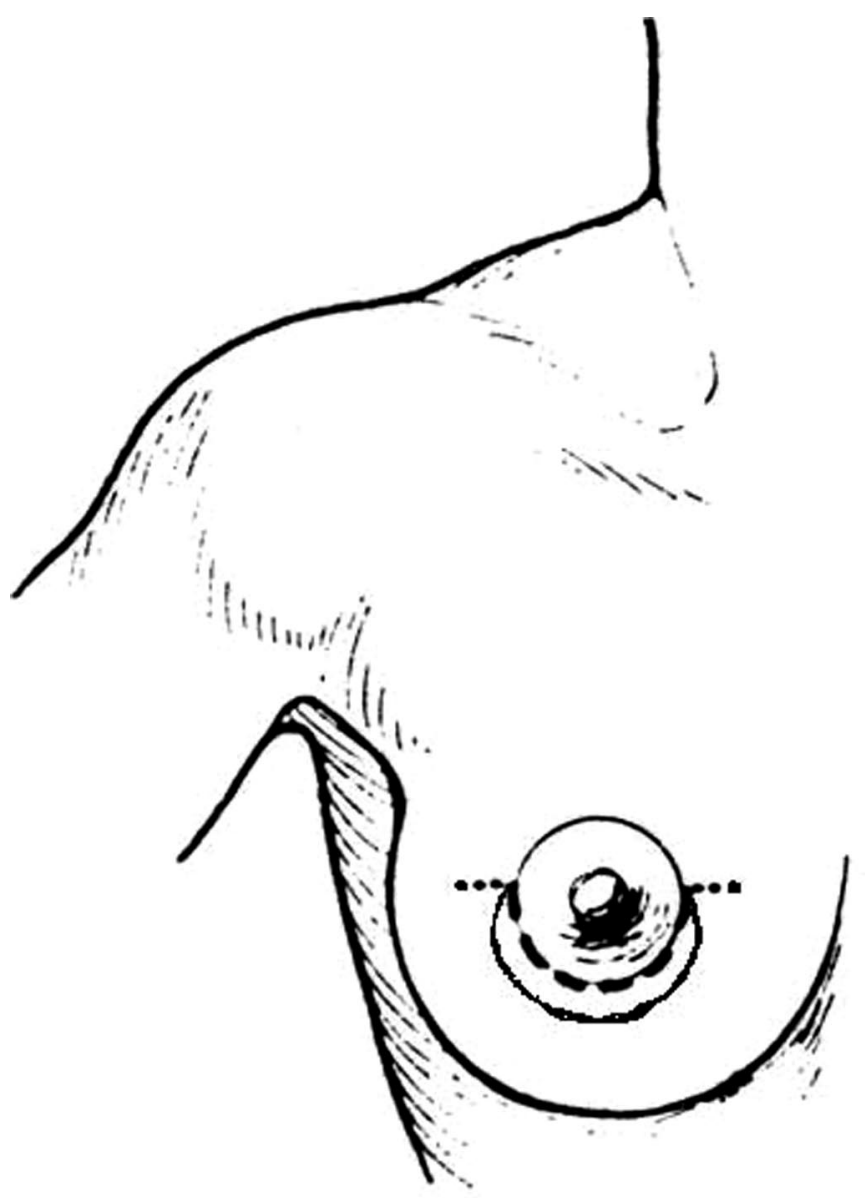

FIGURE 1. Schematic diagram of the modified omega pattern.

\section{REFERENCES}

1. Simon BE, Hoffman S, Kahn S. Classification and surgical correction of gynecomastia. Plast Reconstr Surg. 1973;51:48-56.

2. Rosenberg GJ. Gynecomastia: suction lipectomy as a contemporary solution. Plast Reconstr Surg. 1987;80:379-386.

3. Gasperoni C, Salgarello M, Gasperoni P. Technical refinements in the surgical treatment of gynecomastia. Ann Plast Surg. 2000;44: $455-458$.

4. Smoot EC. Eccentric skin resection and pursestring closure for skin reduction with mastectomy for gynecomastia. Ann Plast Surg. 1998; $41: 378-383$.

5. Tashkandi M, Al Qattan M, Hassanain JM, et al. The surgical management of high-grade gynecomastia. Ann Plast Surg. 2004;53:17-20.

6. Webster JP. Mastectomy for gynecomastia through semicircular intra-areolar incisions. Ann Surg. 1946;124:557-575.

7. Dufourmentel L. L'incision arelaire dans la chirurgie du sein. Bull Emm Soc Chir Paris. 1928;20:9-14

\section{The author responds:}

I thank Dr. Dabernig for his comments and we will take his suggestions into consideration in future sural flap delay procedures.

Detlev Erdmann, MD, PhD

Division of Plastic, Reconstructive, Maxillofacial, and Oral Surgery

Durham, NC detlev.erdmann@duke.edu

\section{Frostbite Injury Due to Improper Usage of an Ice Pack}

\section{To the Editor:}

Ice packs and other cold therapies are frequently applied for the relief of pain, especially around the knee region. They are known for their anti-inflammatory, antispasmolytic effects. They can also reduce edema and swelling. But like every other medical appliances and 


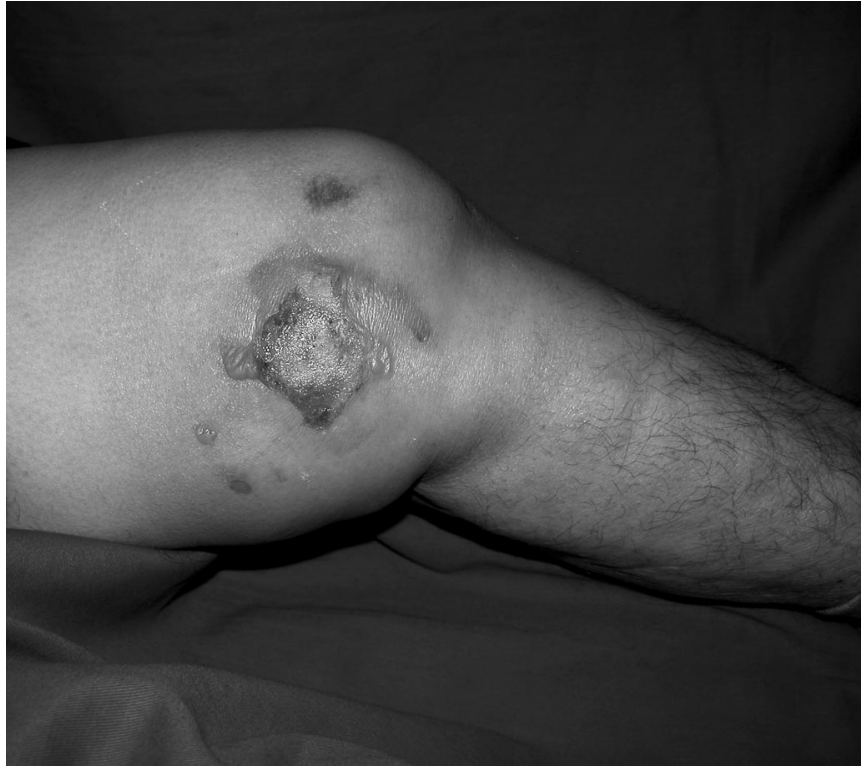

FIGURE 1. Superficial to deep frostbite of the medial aspect of the knee.

drugs, improper usage of the ice packs can end up with serious complications.

We were consulted for a 49-yearold woman who had attempted to use a therapeutic cold pack for a total of 9 days for acute synovial arthritis secondary to gonartrosis. She had applied the frozen ice pack continuously for more than a couple of hours until the pack had warmed to room temperature. On physical inspection, she had Grade II and Grade III frostbite on her medial aspects of the knee where she had applied the ice pack (Fig. 1). She was otherwise healthy. We initially did minor debridement of the blisters and the slough. The wound was followed with daily dressing changes using a chlorhexidine-soaked paraffin dressing for 10 days until the patient's existing lesion recovered without any problem.

Although the basic physiological mechanisms have not been well described, cryotherapy has been shown to decrease skin, muscle, and intraarticular temperatures, decrease metabolism, decrease inflammation, decrease blood flow, decrease pain, decrease muscle spasm, and increase tissue stiffness. The recommended usage of ice packs is to apply it on the sore area for no more than 20 minutes every 2 to 3 hours. It is also recommended to always keep a cloth be- tween the skin and the ice pack. If not used in the recommended way, as in our case, it is likely to end up as frostbite by direct cold injury to cells, ice crystallization of tissues, and poor circulation to the area. To prevent such serious complications, it is important to inform the patient about the seriousness of proper application of the ice pack and to keep in mind to take every therapeutic application seriously, even the ones that seem very simple.

Mustafa Keskin, MD

Zekeriya Tosun, MD

Ahmet Duymaz, MD

Nedim Savacı, MD

Department of Plastic and Reconstructive Surgery

Meram Medical School Selcuk University Konya, Turkey

drmkeskin@hotmail.com

\section{Landmarks for K-Wire Placement in the Distal Phalanx}

\section{To the Editor:}

Positioning a K-wire in the distal phalanx should present no great diffi- culty for the practiced surgeon. Percutaneous K-wire placement through the distal phalanx is frequently performed for fracture fixation and for distal interphalangeal joint fusion.

However, despite the fact the bone is so accessible, poor positioning of $\mathrm{K}$ wires is a regular occurrence with the wires frequently missing the distal phalanx completely (Fig. 1). Most incorrectly placed $\mathrm{K}$-wires are positioned too far on the volar surface. As such, they can only act as a kind of "second-class splint", often located in the soft tissue, flexor tendon, or only partially in the bone. For this reason, the fracture or arthodesis will not stabilize sufficiently, if indeed at all. Some surgeons believe that feeling a resistance when driving in the $\mathrm{K}$-wire is a sign of correct positioning and that everything has been dealt with satisfactorily. If imaging is not carried intraoperatively, the poor result is not recognized until the postoperative $\mathrm{x}$-ray.

Taking into account the close support the distal phalanx provides for the nail bed, we suggest using the arc of the nail as a guide to accurate positioning of $\mathrm{K}$-wires in the distal phalanx. At the finger tip, the landmark for wire placement is found at the intersection of a line between both distal valles unguii and a mediosagittal line from the margo libera of the fingernail (Fig. 2). As second point of reference, the wire should be aimed at a line parallel to the back of the finger at the level of the distal vallum unguis (Fig. 3).

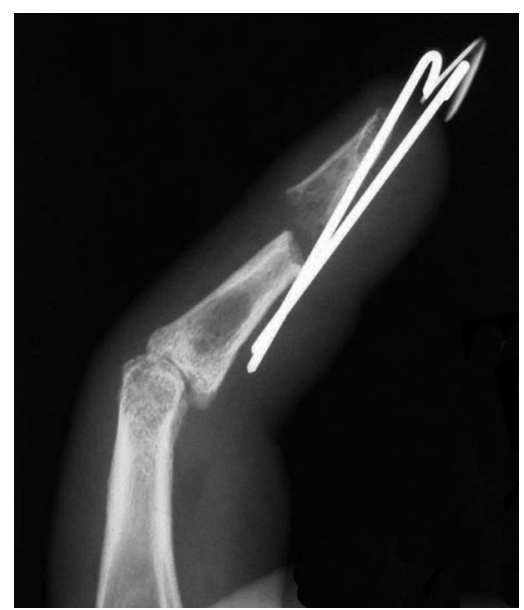

FIGURE 1. X-ray showing failure of Kwire placement in distal phalanx. 


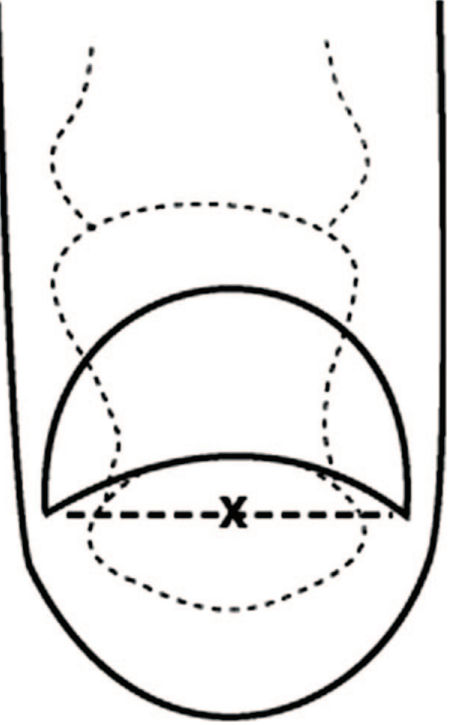

FIGURE 2. Diagram illustrating the ideal position to achieve percutaneous K-wire placement in the distal phalanx.

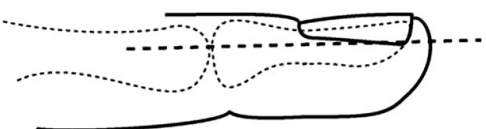

FIGURE 3. Diagram illustrating the ideal position of K-wire placement and the relationship of the distal Phalanx to the overlying nailbed-nail matrix.

We believe that these simple landmarks will increase the chance of accurate placement of $\mathrm{K}$-wires in the distal phalanx, avoid excessive wire passes, and reduce radiation exposure.

John R. Scott, FRCS(Plast) Jörg Dabernig, MD Odhran Shelley, MD Canniesburn Plastic Surgery Unit Jubilee Building Royal Infirmary Glasgow, Scotland, UK joerg.dabernig@gmx.at

\section{The Flap Skin Donor Site: A Good Tool for Monitoring Flap Perfusion}

\section{To the Editor:}

Soft tissue defects often require flap reconstruction or split-skin graft, or a combination of both. In many cases, flap reconstruction will include a skin paddle. We propose that a skin graft can be harvested from the skin paddle of the flap, which both provides a useful tool to monitor the viability of the flap and also provides a donor site of low morbidity.

A part of the split-skin donor site can be used for monitoring in the following fashion. The area used for monitoring is covered with gauze that has been impregnated with heparin. This prevents coagulation in the area used for monitoring. This gauze can be easily removed from the skin graft donor site on the flap paddle and wiped gently with a further heparinsoaked swab to provoke bleeding. This is a simple and safe method of checking flap vitality and avoids unnecessary pinpricking of the flap being monitored. This is particularly useful when less experienced staff may be involved in early flap monitoring as their decisions have far-reaching consequences while on night duty.

Further advantages of this method are a reduction in morbidity when a split-skin graft is required, wise economical use of tissue which has already been used for flap surgery, considerable reduction in postoperative pain after a split-skin graft from an insensitive donor site, and simultaneous reduction in the use of painkillers. We propose this method is simple and efficacious and can be routinely used in the case of flap surgery, as a method to monitor flap perfusion.

Jörg Dabernig, MD Odhran Shelley, MD Stuart Watson, FRCS(Plast) Canniesburn Plastic Surgery Unit Jubilee Building Royal Infirmary

Glasgow, Scotland joerg.dabernig@gmx.at

\section{Flap Skin as a Donor Site for Split Skin Grafts}

\section{To the Editor:}

Nowadays split skin grafts are carried out on a daily basis in many specialist areas of surgery when reconstructing soft tissue defects. Procedures, execution, and physiology of skin grafts are sufficiently established. In principal, skin for grafts can be taken from anywhere on the body; however, the upper thigh is preferred as the donor region. The disadvantages of a split skin removal are a noticeable scar at the donor site and long-lasting painfulness at the site of removal, the degree of these depending on the thickness and special nature of the skin taken for the graft.

However, in the case of large defects with important structures exposed, a reconstruction can only be carried out using flap surgery. The whole defect can frequently not be completely covered by the flap and the skin paddle belonging to the flap because attention has to be paid to a direct closure of the flap donor site. The flap itself often needs to be covered on the flap muscle area by means of a skin graft. Further defects frequently exist in the trauma zone in parallel to the main defect site and have to be covered by means of a split skin graft.

When performing plastic surgery with flaps, whether pedicled or free, the skin paddle attached to the flap has always been found to be insensitive. Likewise, insensitive regions can be found in the vicinity of flap donor areas, as when a sensitive branch of skin has to be cut through or lifted to provide a nerve supply for the flap. As these areas are no longer connected with the central nervous structures, they are insensitive to pain. Taking this into consideration, a pain-free split skin removal can be carried out. We use this method in pedicled fasciocutaneous or musculocutaneous flap surgery. Furthermore, it is used after anterolateral thigh flap harvesting, as the skin nerve is cut through when lifting the flap.

If the above-mentioned factors are at hand when planning a reconstruction, this method is indicated. We would like to point out the possibility of a split skin graft in insensitive flap areas or the neighboring insensitive areas after the flap has been lifted. This appears to us to be a very meaningful possibility for reducing donor site morbidity. As no additional area needs to be involved to serve as donor site for a split skin graft, good economical use is made of the tissue. A further important advantage of this method, which is worthy of mention, is the postoperative pain re- 


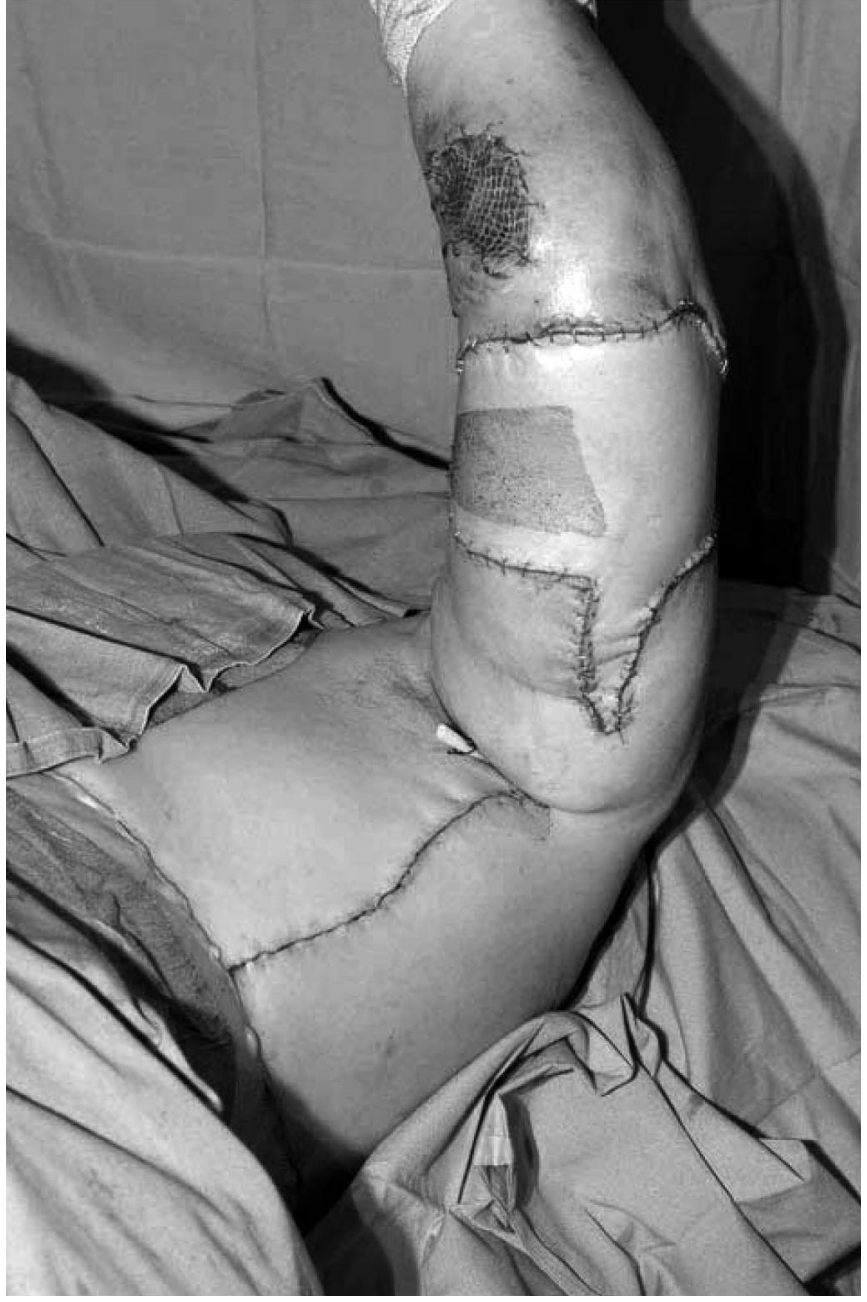

FIGURE 1. Application of the method described in the text, with a harvested SSG to cover an additional defect in the trauma zone. The graft is taken from the skin paddle of the flap, which is an insensitive donor site.

duction at the donor site. From experience, most pain is caused at this site; this situation can be avoided in the future, which also leads to a conspicuous reduction in the use of painkillers.

This method (Fig. 1), which is carried out routinely in our department, leads to a rational economic use of the tissue employed, to a reduction in donor site morbidity, to a significant reduction in postoperative pain, and to a reduction in postoperative pain medication.

Jörg Dabernig, MD Stuart Watson, FRCS(Plast) Canniesburn Plastic Surgery Unit Jubilee Building Royal Infirmary Glasow, Scotland joerg.dabernig@gmx.at

\section{An Alternative Approach to the Delayed Sural Flap}

\section{To the Editor:}

We read with interest the recent article by Erdmann et $\mathrm{al}^{1}$ in Annals of Plastic Surgery and congratulate them on their successful use of the delayed sural flap in a difficult patient group. Since the original description of the sural flap by Masquelet et al, ${ }^{2}$ this flap has been modified and used widely within Plastic Surgery for lower limb reconstruction. ${ }^{3-5}$ The findings certainly indicate that caution needs to be taken when using the sural flap in high-risk patients. We agree that the delayed sural flap is a useful technique, particularly for patients with significant comorbidity where free tissue transfers are high risk and operation time needs to be kept to a minimum. In addition, the sural flap can be raised under regional anesthesia, obviating the need for a general anesthetic. For these reasons, the sural flap is routinely used within our unit, often as a delayed procedure, when the patient's comorbidity precludes free tissue transfer.

From our experience of using the delayed sural flap, we would like to suggest several alternative points of technique that do not compromise the safety of the flap, even in high-risk patients. First, we would disagree with Erdmann ${ }^{1}$ that the proximal neurovascular bundle needs to be left intact until the second procedure. It can be safely divided and the flap based upon the distal pedicle, provided the flap is replaced in its original anatomic position without tension. This improves the reorientation of blood flow (delay phenomenon) and increases the chances of flap survival after transposition. In our hands, this has resulted in complete flap survival, including in high-risk patients. Second, we do not feel that positioning a glove under the flap during the delay procedure is necessary. Without using a glove, raising the flap from the donor site after 2 weeks can be achieved without difficulty, using fingertip dissection, as minimal adhesions have occurred at this stage. This has the advantage of reducing the infection risk inherent with the insertion of a foreign body, especially in patients with comorbidity, such as diabetes. Third, we recommend strict leg elevation, for a minimum of 7 days, to reduce the high rate of venous congestion associated with the sural flap. We would also recommend taking a subcutaneous vein with the flap during the initial flap-raising procedure. This can subsequently be microsurgically anastamosed to a local vein if venous congestion remains a problem after flap transposition and insetting.

Overall, we agree that the delayed sural flap is a useful flap in a select group of patients with significant comorbidity that would preclude free tis- 
sue transfer. With our suggested modifications the delay procedure is safe, does not compromise the chances of flap survival, and avoids the need for the insertion of foreign material with its associated increased infection risk.

Jörg Dabernig, MD David J. McGill, MRCS(Ed) Canniesburn Plastic Surgery Unit Jubilee Building Royal Infirmary Glasgow, Scotland, UK joerg.dabernig@gmx.at

\section{REFERENCES}

1. Erdmann D, Gottlieb N, Humphrey JS, et al. Sural flap delay procedure. A preliminary report. Ann Plast Surg. 2005;54:562-565.

2. Masquelet AC, Romana MC, Wolf G. Skin island flaps supplied by the vascular axis of the sensitive superficial nerves: study and clinica experience in the leg. Plast Reconstr Surg. 1992;89:1115-1121.

3. Price MF, Capizzi PJ, Watterson PA, et al. Reverse sural artery flap: caveats for success. Ann Plast Surg. 2002;48:496-504.

4. Chen SL, Chen TM, Chou TD, et al. Distally based sural fasciomusculocutaneous flap for chronic calcaneal osteomyelitis in diabetic patients. Ann Plast Surg. 2005;54:44-48.

5. Baumeister SP, Spierer R, Erdmann D, et al. A realistic complication analysis of 70 sural artery flaps in a multimorbid patient group. Plast Reconstr Surg. 2003;112:129.

\section{Debulking of Free Perforator Flaps for Head and Neck Reconstruction Using an Arthroscopic Shaver}

\section{To the Editor:}

Free flap contouring in head and neck reconstruction is commonly performed at the end of therapy. The cosmetic result of a free flap is unpredictable during the main reconstructive procedure. Several factors such as flap contracture, postoperative radiotherapy, and muscle atrophy due to denervation affect the wound healing. For these reasons, the common approach is to provide a reconstruction with a flap larger than necessary. Usually after the completion of the therapy for the cancer, several ancillary procedures have to be performed to obtain symmetry and con-

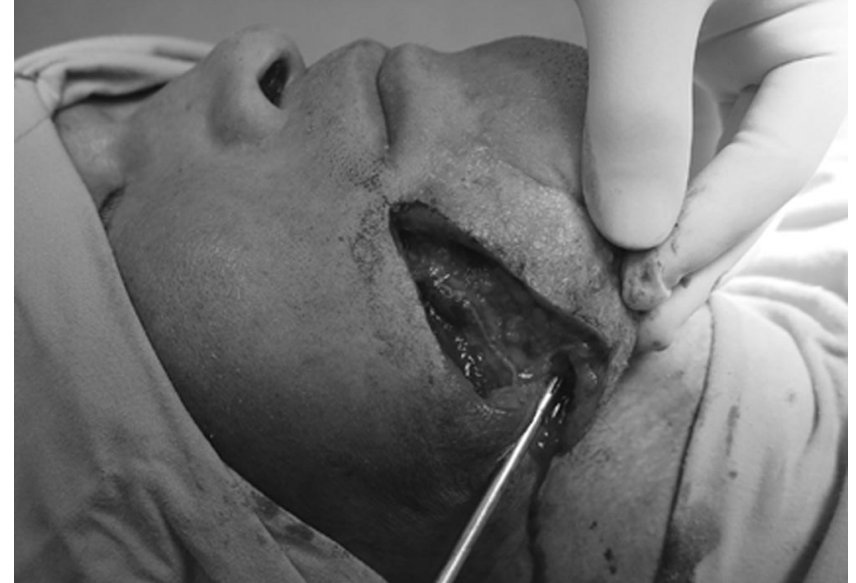

FIGURE 1. The incision of a skin excision is used to reach different layers to be debulked.

tour. Traditionally, surgical excision of the subcutaneous fat or liposuction systems (suction assisted, ultrasound, laser, or power assisted) are used to debulk the flap. ${ }^{1,2}$ The surgical excision, the most commonly used procedure, may cause partial or total flap failure in case of damage of the pedicle or the perforator of the flap particularly if performed in early stages. ${ }^{3}$ Moreover, liposuction systems are effective with the subcutaneous fat but not with fibrotic tissues. We successfully used an arthroscopic shaver for flap debulking in 11 patients. The arthroscopic shaver system is a motorized system consisting of an outer hollow sheath and an inner hollow rotating cannula with corresponding windows (Fig. 1). ${ }^{4}$ The window of the inner sheath function as a cylindrical blade that rotate into the outer sheath and cut the soft tissues sucked in by a suction system. The procedure is easy and can be performed under local anesthesia using commonly available arthroscopic instruments. A small incision is all that is needed to allow the shaver to enter the selected layer to be debulked. The incision used for a scar revision, skin excision, or local plasty can be used as an alternative way to reach different layers to be contoured (Fig. 1). The device allows easy removal of fibrotic tissues on the submucosal plane of the oral cavity, which is particularly difficult with liposuction after radiotherapy. The shavers have a blunt tip and are side-cutting causing minimal damage to vessels.
No complications such as infection, seroma, hematoma, altered sensation, contour irregularities, or skin necrosis have been encountered in our series.

The results were cosmetically acceptable; the procedure is easy and cost effective since the device is available in hospitals with orthopedic departments.

Emanuele Cigna, MD

Department of Plastic Surgery E-Da Hospital/I-Shou University Yan-chau Shiang, Taiwan

Department of Plastic Surgery University of Rome

La Sapienza, Italy emanuelecigna@msn.com

Paolo Sassu, MD

Prashanth Varkey, MBBS, MS, MCh Ngian Chye Tan, MBBS

Yi-Tien Liu, MD

Department of Plastic Surgery E-Da Hospital/I-Shou University Yan-chau Shiang, Taiwan

\section{REFERENCES}

1. Hallock GG. Defatting of flaps by means of suction-assisted lipectomy. Plast Reconstr Surg. 1985;76:948-952.

2. Yamanaka K, Ichikawa T, Horiuchi Y. Flap defatting with an ultrasonic surgical aspirator Plast Reconstr Surg. 1997;99:888-891.

3. Hallock GG. Conventional liposuction-assisted debulking of muscle perforator flaps. Ann Plast Surg. 2004;53:39-43.

4. Canale ST. Campbell's Operative Orthopedics. 10th ed. Mosby 2003; pp 2501-2502. 


\section{Ectopic Bone Formation Following Temporalis Muscle Transposition for Facial Paralysis: A Rare Complication?}

\section{To the Editor:}

Ectopic bone formation following tem-poralis muscle transposition for congenital facial paresis has been reported only twice previously in children. ${ }^{1,2}$ A case of ectopic bone formation following masseter muscle transposition has also been reported. ${ }^{3}$

We report another similar case of a 17-year-old girl with left-side congenital facial nerve palsy. At the age of 6, she had reconstruction with a temporalis muscle transposition in another hospital. She came to our clinic at the age of 17 , seeking further esthetic improvement.

On examination, it was noted that she had a hard, irregular prominence in her left cheek, a hollow temporal fossa deformity, lagophthalmus of the left eye, and a very limited movement of the angle of the mouth while smiling (Fig. 1). A computed tomography scan showed subcutaneous ectopic bone formation in the cheek, pulling at the angle of the mouth on animation (Fig. 2). This ectopic bone was resected using the previous preauricular incision (Fig. 3). In the same operation, a silicone spacer was implanted in the temporal hollow, and lateral tarsorrhaphy of the left eye was preformed, with marked improvement in the patient's appearance.

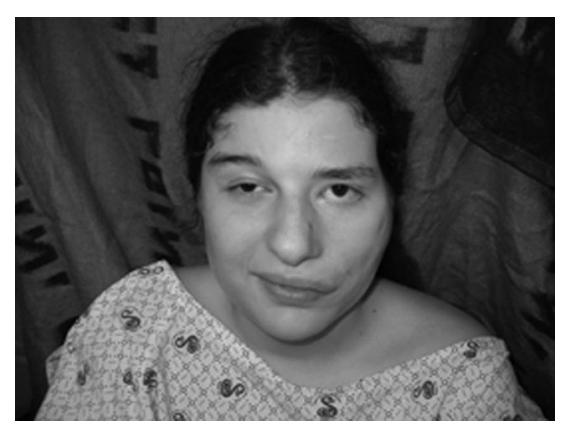

FIGURE 1. Preoperative view, patient at age 17 years.

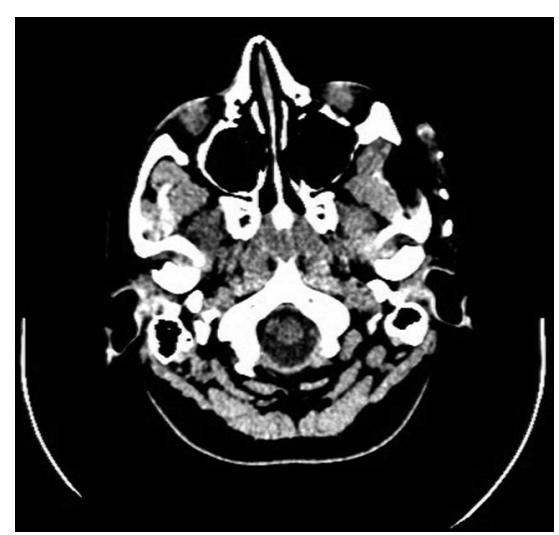

FIGURE 2. Axial computed tonography scan demonstrating ectopic ossification of transposed temporalis muscle in the left cheek.

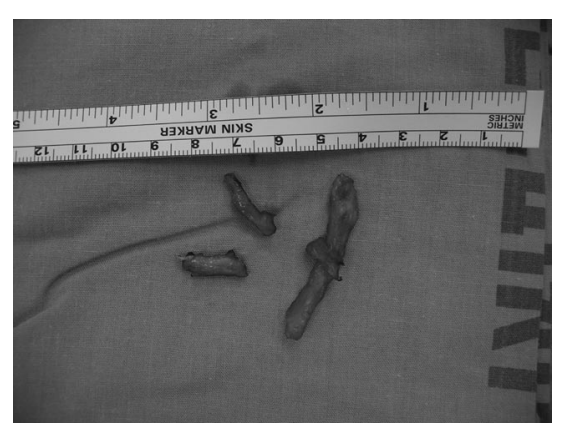

FIGURE 3. Ectopic bone fragments.

A few possible explanations for ectopic bone formation in these cases have been suggested. A likely explanation is ectopic bone formation from transfer of periosteum with the muscle flap. ${ }^{3}$ Ectopic bone formation can also follow soft-tissue trauma or surgery. ${ }^{4}$ We would like to suggest that this complication might not be as rare as has been thought and should be expected whenever temporalis muscle transfer is done in children. Therefore, care should be taken to avoid including the periosteum in muscle transfer operations, especially in children.

Neta Adler, MD Plastic Surgery Department Rabin Medical Center

Petah Tikva, Israel netaadle@post.tau.ac.il.

Batya Yaffe, MD Hand Surgery Department Sheba Medical Center Ramat Gan, Israel

\section{REFERENCES}

1. Bakker RX, Nicolai JPA. Ectopic bone formation after temporal muscle transposition for facial paralysis. Plast Reconstr Surg. 2000;105: 2079-2081

2. Davis C, Glasson D. Ectopic bone formation following temporalis muscle transposition for facial paralysis. Plast Reconstr Surg. 2001;107: 1918-1919.

3. Dubin BJ, Kaplan EN. Osteophyte formation following masseter muscle transfers for facial paralysis: case report. Plast Reconstr Surg. 1977;59:758-759

4. Gear AJ, Buckley C, Kaplan F, et al. Multifactorial refractory heterotopic ossification. Ann Plast Surg. 2004;52:319-324.

\section{Lasers and Light Devices $A$ to $Z$}

V arious lasers and light technology devices are now available on the international market for plastic surgery. However, most do not have an established record of safety in Japan. I recently encountered patients with complications of these "unknown imported devices" and realized that plastic surgeons should know at least "what they are." Therefore, I prepared the following "A to Z" for quick reference. Over 160 devices were referred. Readers are invited to add to and revise this information.

Manufacturer, product, composition, indication (A, acne: $\mathrm{C}$, cellulite: $\mathrm{H}$, hair removal: L, low-level laser therapy: $\mathrm{T}$, Tatoo: $\mathrm{S}$, surgery: $\mathrm{R}$, rejuvenation: $\mathrm{V}$, vein: $\mathrm{Vx}$, varicose vein: $\mathrm{W}$, wrinkle):

Adept Medical, UltraWave I-III/A/ YAG, Nd:YAG/Alex, H/R/V, SpectraPulse Ultra, IPL, H/R, UltraLight 532, Diode, $\mathrm{H}$

Aesthera, Photopneumatic system, Vacuum +IPL, V/H/R Alderm, Omnilux, LED, A/R, HR-Force, Didode, H

American Medical Bio Care, Omnilight FPL, IPL, H/R/V, Novalight FPL, IPL, A/H/R/V

Archer Medical, Quadraz, Er:YAG/ Nd:YAG/AlexR/H/V/T

BioCell, MediDerm, Er:YAG, R/W

Biolitec, Ceralas, Diode, V

Candela, Ellipse I2PL(DDD), I2PL, R/V, GentleLase, Alex, H/R/V, GentleYAG, Nd:YAG, H/V, C beam, Dye, V, $\mathrm{V}$ beam, Dye, A/V/W, Smoothbeam, Diode, $\mathrm{A} / \mathrm{W}$ 
Cooltouch, CoolTouch CT3, 1320nm Nd:YAG, A/W, CoolTouch CTEV, 1320 nm Nd:YAG, Vx, CoolTouch Varia, Nd: YAG, $\mathrm{H} / \mathrm{V}$

Cosmetic Solutions, HexEpi, IPL, H, PhotoJuvena, IPL, R, PJ Mini, IPL, R

CureLight, iClear/XL, IPL, A/R, MultiClear, tunable UV, A/Vitiligo

Cutera, CoolGlide Classic/CV/Excel/Vantage, Nd:YAG, H/R/V, CoolGlide Xeo/Genesis Plus, Nd:YAG/IPL, H/V/R/W, Omnilux, LED, A, Titan, 1100- to 1800-nm light-based system, R/W, Solera Opus, IPL, H/R, XeoSA, IPL, R

Cynosure, Acclaim 7000, Nd: YAG, H/R/V, Apogee 550/9300, Alex, $\mathrm{H}$, Apogee Elite, Alex/Nd:YAG, H/R/V, $\mathrm{CO}_{3}$ system, Er:YAG, R, Cynergy/III/ PL, Dye/Nd:YAG/IPL, H/R/V/W, Photogenica $\mathrm{V} / \mathrm{V}-\mathrm{Star}, \mathrm{R} / \mathrm{V} / \mathrm{W}$

DEKA, Exiclite, eximer, Vitiligo/alopecia, Photolight/Photosilk, IPL/Er:YAG/ Nd:YAG,A/H/R/V/W, SmartEpil II plus, Nd:YAG, H/V, SmartLipo, Nd:YAG, S/Lipolysis, SmartXide, $\mathrm{CO}_{2}$, Surgery/A/R, Triactive, Diode/Vacuum, $\mathrm{C}$

DermaMed USA, Quadra Q4/Platinum, H/R/V DermaVista, Cold Light, LED, R, VascuTouch, RF, V

Diomed, EVLT, Diode, Vx

Dusa, BLU-U+Levulan, LED+ ALA, A

Edge Systems, Delphia del sol, LED, A/R

Erchonia Mediocal, Erchonia 3LT laser, Diode, L

E.U.photonics, N-lite, Dye, R/W Europro, Phytoscan Coolight HFD,

HFD Cold laser, H/R/W

Flip 4, Max7, LED, A/R

Focus Medical, NatuLase 1064/

LP, Nd:YAG/long pulse, H/R/V/W, NatuLase Erbium, Er:YAG, R/W

Fotona, Dualis/Fidelis XS, Er:YAG, A/R, Dualis/Fidelis XP, Nd:YAG, H/V, Dualis VP, Nd:YAG+KTP, V, Dualis SP, Nd:YAG+Er:YAG, R

FrendlyLight, FrendlyLight Er: YAG, Er:YAG, R/W, FrendlyLight Nd: YAG, Nd:YAG, H/R/V/W

Hoya ConBio, Medlite C3/C6, Nd: $\mathrm{YAG}, \mathrm{A} / \mathrm{H} / \mathrm{R} / \mathrm{T} / \mathrm{V}$ $\mathrm{A} / \mathrm{R} / \mathrm{W}$
Iridex, Apex 800, Diode, H/R, DioLite 532, Diode, R/V, VariLite, 532/ $940 \mathrm{~nm}$ diode, $\mathrm{A} / \mathrm{H} / \mathrm{R} / \mathrm{V}$

Kakinuma Medical, MT-15A, $\mathrm{CO}_{2}, \mathrm{~S}$

Laserscope, Gemini, Nd:YAG/ KTP, A/H/R/V/W, Solis, IPL, R/H, Aura-i, KTP, R/V, Lyra-i, Nd:YAG, H/R/V/W, Venus-i, Er:YAG, R/W

Light Age, EpiCare LP/LPX, Alex, H/R/T/V, Q Clear, Nd:YAG/KTP H/R/T/V, Ta2 Eraser, Alex, T/H LED, R

Light Bioscience, GentleWaves,

Luminus, Aluma, Vacuum-assisted bipolar RF, W, B clear, UV, Vitiligo, Clear 100, IPL(Blue), A, ClearLight, IPL(Blue), A/R, D-light SR, IPL, R/V, Luminus One, Diode/IPL/Nd:YAG, H/V, LightSheer ET/ST/XC, Diode, H, IPL Quantum SR/DL, IPL/Nd:YAG, R/V, VascuLight Elite, IPL/Nd:YAG, R/V, ReLume, UV, repigmentation, Sharplan SurgiTouch, $\mathrm{CO}_{2}, \mathrm{~S} / \mathrm{R}$, Ultrapulse Encore/ $5000 \mathrm{C}, \mathrm{CO}_{2}, \mathrm{R}$

M\&M, Stage MY-100, Nd:YAG, S, Sopia, Nd:YAG, H, M-Laser MC70SP, $\mathrm{CO}_{2}$, S, RD-1200, Ruby, R, Multilaser 5 MLF-601, diode, L, MediLux, IPL, R

Max Engineering, Spectra SP, $\mathrm{CO}_{2}$, S, Spectra VRMII, Nd:YAG, T/R Med-Surge Tech, ATHOS, Nd: YAG, H/V, ARAMIS, Er:Glass, A/R, DermAblative MCL30, Er:YAG, R, VIRIDIS, Diode, V, MedioStar, Diode, H, Prolite II, Diode, $\mathrm{H}$

Mochida,Medilaser20DL/Soft1000, Diode, S/L, Medilaser RF/30AF, $\mathrm{CO}_{2}, \mathrm{~S}$

NIDEK, Curia/plus, Diode, H/R, UniPulse, $\mathrm{CO}_{2}, \mathrm{~S}$

NIIC, Lazery15Z, $\mathrm{CO}_{2}, \mathrm{~S}, \mathrm{QL} 10 \mathrm{Y}$, Nd:YAG, S, IB101, Ruby, R, DO101, Dye, $\mathrm{V}$

Norseld, Dual Yellow, Copper Bromide, A/R/V

Novalis, Clareon SR/HR/AR/VR,

IPL, A/H/R/T/V, Solarus SR/HR/AR, $\mathrm{A} / \mathrm{H} / \mathrm{R} / \mathrm{T} / \mathrm{V}$

OptoGenesis, EpiCool Platinum/HR SR, IPL, H/R/V/W

Opusmed, F1 Diode Laser, Diode,

H, Lumiphase-R, LED, A/R

Orion Lasers, Harmony, Advanced

Inner Act, LiteLift/Medical, LED, Fluorescent Technology/Pulsed UVB/Nd: YAG, R/V/T/V, Sonata, Diode, $\mathrm{H}$
Palomar, SturLux G/R/Rs/V/Y, IPL, A/H/R, SturLux 1064, Nd:YAG, R, MediLux, IPL, A/H/R/V, EsteLux B/G/ $\mathrm{R} / \mathrm{Rs} / \mathrm{V} / \mathrm{Y}, \quad \mathrm{IPL}, \mathrm{A} / \mathrm{H} / \mathrm{R} / \mathrm{V}$, NeoLux R/Rs, H, SLP1000, Diode, H/V, Q-YAG 5, Nd:YAG, R

PhotoMedex, XTRAC, Excimer, Vitiligo

PhotoTherapeutics, OmniLux, LED, A/R

Quantel Medical, Aramis, Er glass, R/A, Prolite II, IPL, H/R/V, Viridis Derma, KTP, V/R

Radiancy, SPR, IPL + heat, R/V, Skin Station, IPL, H/R/V, SpaTouch/Pro, IPL + heat, H, Whisper, Er:YAG, R/W

Reliant, Fraxel SR, Diode fiber, R/W Revitalight, Revitalight, LED, A/R Rhytec, Portrait PSR3 (Gyrus Plasma

Skin Regeneration Technology), R/W

Sciton, Profile ClearScan/Therma Scan/Contour/BBL, Nd:YAG/Er:YAG/ IPL, A/R/H/V/W

Silhouet-Tone, Soli-Tone, LED+Micronized HF polarized currents, A/R/W

SSI Laser Engineering, Ultra MD, $\mathrm{CO}_{2}, \mathrm{~S} / \mathrm{R}$

Symedex, SpectraClear, IPL, A/H, LaserPeel 3D, Er:YAG, R, DermoSonic, Ultrasonic, C, SkinMaster, Ultrasound/ Microlaser, R Syneron, Comet, Diode + RF, $\mathrm{H}$, Aurora AC/DS/SR/DSR, IPL+RF, $\mathrm{A} / \mathrm{H} / \mathrm{R} / \mathrm{V}$, Polaris DS/V/WR, H/V/R/W, Galaxy, IPL/Diode+RF, A/H/R/V/W, VelaSmooth, IPL +RF+Vacuum, C, Pitanga, IPL + RF, H

Telsar, Softlight, Nd:YAG, H/R

Terabyte, Terabyte2000 A/B/C, Diode, $\mathrm{A} / \mathrm{H} / \mathrm{R}$

Thermage, ThermaCool, RF, W

UltraShape Inc., Contour 1, Ultrasound, Fat

VNUS Medical Technologies, Closure, RF, Vx

WaveLight, ARION, Alex, H, MYDON, Nd:YAG, H/V, BURANE/ XL, Er:YAG, R, SINON, Ruby, R, TALOS, Excimer, Vitiligo

Yoshida, OpelaserPro/SP/One, $\mathrm{CO}_{2}$, S, Opelaser Lite/Nd2, Nd:YAG, S, Trinpl D, Diode, L

Kota Ichikawa, MD Department of Plastic Surgery Tokai University School of Medicine Kanagawa, Japan ichikota@is.icc.u-tokai.ac.jp 